\title{
Polymorphisms in miRNA genes play roles in the initiation and development of cervical cancer
}

\author{
Zhiling Yan ${ }^{2 *}$, Ziyun Zhou1 ${ }^{*}$, Chuanyin Li1 ${ }^{1}$, Xielang Yang ${ }^{2}$, Longyu Yang ${ }^{1}$, Shuying Dai ${ }^{3}$, Jiehan Zhao ${ }^{4}$, \\ Huijing $\mathrm{Ni}^{2}$, Li Shi ${ }^{\boxplus}$ and Yufeng Yao ${ }^{1 凶}$ \\ 1. Institute of Medical Biology, Chinese Academy of Medical Sciences \& Peking Union Medical College, Kunming 650118, China \\ 2. Department of Gynaecologic Oncology, The 3rd Affiliated Hospital of Kunming Medical University, Kunming 650118, China. \\ 3. School of Basic Medical Science, Kunming Medical University, Kunming 650500, China \\ 4. Department of Pharmacology, Faculty of Science, University of Alberta, Edmonton, Canada \\ *These authors contributed equally to this work.
}

$\triangle$ Corresponding authors: Prof. Li Shi, Institute of Medical Biology, Chinese Academy of Medical Sciences \& Peking Union Medical College, Kunming 650118, Yunnan, China. Email address: shili.imb@gmail.com and Dr. Yufeng Yao, Institute of Medical Biology, Chinese Academy of Medical Sciences \& Peking Union Medical College, Kunming 650118, Yunnan, China. Email address: leoyyf@gmail.com or yufeng_yao@imbcams.com.cn

(C) The author(s). This is an open access article distributed under the terms of the Creative Commons Attribution License (https://creativecommons.org/licenses/by/4.0/). See http://ivyspring.com/terms for full terms and conditions.

Received: 2019.01.25; Accepted: 2019.07.02; Published: 2019.08.20

\begin{abstract}
MicroRNA deregulation is crucial for cancer development. Studies showed that polymorphisms in miRNA genes could affect miRNA expression, which might be associated with cancer development. In the current study, we investigated the association of seven single nucleotide polymorphisms (SNPs) in seven miRNA genes with the initiation and development of cervical cancer in a Chinese Han population. The SNPs of 358 cervical intraepithelial neoplasia (CIN) patients, 547 cervical cancer patients and 567 healthy individuals were genotyped using TaqMan assays. Moreover, we evaluated the association of the seven SNPs with the different stages of cervical cancer. Our results showed that rs4636297 in miR-126 was associated with susceptibility to $C I N$ and cervical cancer $(P=0.019$ and 0.019 , respectively) and that the $\mathrm{T}$ allele was associated with a higher risk of $\mathrm{CIN}(O R=1.334,95 \% \mathrm{Cl}$ : 1.049-1.698) and cervical cancer $(O R=1.296,95 \% \mathrm{Cl}: 1.044-1.609)$. Similarly, rs 11614913 in miR-125a was associated with $\mathrm{CIN}$ and cervical cancer $(P=0.025$ and 0.015 , respectively), and the $T$ allele might be the protective factor for $C I N$ $(O R=0.807,95 \% \mathrm{Cl}: 0.669-0.974)$ and cervical cancer $(O R=0.814,95 \% \mathrm{Cl}: 0.689-0.961)$. Our results indicated that rs4636297 in miR-126 and rs11614913 in miR-196a2 play an important role only in the initiation of cervical cancer not in the development of CIN to cervical cancer.
\end{abstract}

Key words: microRNA, Polymorphisms, CIN, Cervical cancer, Association, Chinese Han population

\section{Introduction}

Cervical cancer is the second most common malignant tumour among women after breast cancer worldwide[1]. Most cervical cancers (up to $99 \%$ ) are associated with oncogenic human papillomavirus (HPV)[2]. However, almost all low-risk HPV infections and more than two thirds of high-risk HPV infections are eradicated over a 24-month period[3, 4], and only a small fraction of women infected with HPV will develop cervical cancer[5]. Thus, other factors might also be important during the initiation and development of cervical cancer, such as host genes, reproductive behaviour[6], sexual activity[7] and nutritional factors[8].
MicroRNAs (miRNAs) are a group of short, single-stranded, non-coding RNAs (approximately 18-25 nucleotides in length) that regulate the expression of up to $30 \%$ of human genes through targeting the $3^{\prime}$-untranslated region (3'-UTR) or 5'-UTR [9]. Therefore, miRNAs are involved in almost every biological process, such as proliferation[10], apoptosis[11], migration and invasion[12]. In cervical cancer, abundant miRNAs were found to be restored, and this process was related to cervical cancer development and prognosis[13, 14]. The lengths of miRNA genes are usually significantly shorter than those of coding genes; consequently, single nucleotide 
variations (like single nucleotide polymorphisms, SNPs) in miRNA genes could affect mature progression of miRNAs, resulting in aberrant gene expression[15, 16], which might be the mechanism through which SNPs in miRNA genes are associated with human cancer susceptibility[17-22]. In 2016, Wang et al. demonstrated that a polymorphism in miR-155 was associated with cervical cancer risk[23]. Moreover, our previous study showed that rs11134527 in miR-218 and rs531564 in miR-124 were associated with cervical cancer susceptibility in a Chinese Han population[24].

In the current study, we investigated the distribution of another seven SNPs in miRNA genes (rs543412 in miR-100, rs999885 in miR-106b, rs1143770 in let7-a-2, rs2296616 in miR-107, rs8111742 in miR-125a, rs4636297 in miR-126 and rs11614913 in miR-196a2) in the different steps of cervical cancer (CIN and cervical cancer). Moreover, we analysed the association of these SNPs with the initiation and development of cervical cancer.

\section{Methods}

\section{Ethical approval and informed consent}

All procedures were in accordance with the ethical standards of the responsible committee on human experimentation and with the Helsinki Declaration of 1964, which was revised in 2013. All experimental protocols used in this study were approved by the Institutional Review Boards of the No. 3 Affiliated Hospitals of Kunming Medical University. All participants provided written informed consent.

\section{Study population}

In the current study, 358 patients with CIN and 547 patients with CC were recruited after diagnosis according to "Diagnosis and Treatment Obstetrics and Gynaecology" and FIGO stage (International Federation of Gynaecology and Obstetrics, 2009) at the 3rd Affiliated Hospital of Kunming Medical University from 2012-05 to 2016-08. The inclusion criteria: (1) the CIN and cervical cancer patients were diagnosed according to "Diagnosis and Treatment Obstetrics and Gynaecology" and International Federation of Gynaecology and Obstetrics, 2009; (2) the patients in case groups were not suffering with any other malignancy, and the control individuals had no history of cancer and other chronic diseases; (3) the patients had not received preoperative neoadjuvant therapies (including chemotherapy and radiotherapy). The exclusion criteria: (1) the patients with a prior history of primary cancer other than cervical cancer; (2) the patient with malignant tumors except cervical cancer; (3) the patients receiving radio therapy or chemotherapy, and unclear pathological diagnosis. Over the same period, 567 healthy women from the healthy screening project at the same hospital served as the healthy controls in the current study.

\section{SNP selection and genotyping}

All SNPs selected had minor allele frequencies in the Chinese Han population greater than $5 \%$ in the Ensembl database (http://asia.ensembl.org/index. html). SNP-rs999885 is located in the promoter region, while the other SNPs are located in the prI-miRNA sequence. These regions are associated with miRNA gene transcription or miRNA processing and maturation.

Venous blood of the subjects was collected into anticoagulant tubes, and the genomic DNA was extracted from peripheral lymphocytes using a QIAamp Blood Mini Kit (Qiagen, Hilden, Germany). The seven SNPs in the miRNA genes were genotyped using TaqMan Assays. The probes and primers were designed and produced by Thermo Fisher Scientific Company (Waltham, MA, USA), and the TaqMan Master Mix was also from Thermo Fisher Scientific Company. The PCR amplifications were carried out in 384-well reaction plates (MicroAmp ${ }^{\mathrm{TM}}$ Optical 384Well Reaction Plate, Thermo Fisher Scientific Company). The amplification system comprised $2.5 \mu \mathrm{L}$ $2 \times$ Master Mix, $0.125 \mu \mathrm{L} 40 \times$ primer and probe (FAM and VIC) mix, $1.375 \mu \mathrm{L} \mathrm{ddH}_{2} \mathrm{O}$ and $1 \mu \mathrm{L}$ genomic DNA (equivalent $\mathrm{ddH}_{2} \mathrm{O}$ in the negative control). The amplification was conducted in a QuantStudio 6 Flex Fast Real-Time PCR system using the following conditions: $95^{\circ} \mathrm{C}$ pre-heat denaturing for $10 \mathrm{~min} ; 92^{\circ} \mathrm{C}$ heat denaturing for $10 \mathrm{~s}$ and $60{ }^{\circ} \mathrm{C}$ annealing and extension for $1 \mathrm{~min}$, all repeated for 40 cycles. The data were analysed using QuantStudioTM real-time PCR software (Thermo Fisher Scientific Company). The genotyping results were confirmed through sequencing the SNPs from the subjects with each genotype.

\section{Statistical analysis}

The statistical analyses were performed using SPSS 19.0 software (IBM Corporation, Armonk, New York, USA) and Microsoft Excel (Microsoft Corporation, Redmond, Washington, USA). The representativeness of the subjects in the current study was evaluated using the Hardy-Weinberg equilibrium (HWE). Logistic regression was used to evaluate the effects of the SNPs on the risk of cervical cancer development with age as a covariate, and ORs with 95\% confidence intervals (CIs) were calculated. The effects of the SNP genotypes on the risk of cervical cancer were analysed using inheritance model 
analysis. Three inheritance models, namely, codominant, dominant and recessive, were analysed using SPSS. A $P$ value less than 0.05 was considered statistically significant for statistical analysis.

\section{Results}

\section{Subject characteristics}

The characteristics of the individuals enrolled in present study are listed in Table 1 . The ages of the $\mathrm{CIN}$, cervical cancer and control groups were not significantly different $(P>0.05)$. In the CIN group, 34 patients had low-degree CIN (CIN 1), and 324 had high-degree CIN (CIN 2-3). In the cervical cancer group, there were 447 patients with squamous cell carcinoma (SCC), 87 patients with adenocarcinoma (AC) and 13 patients with other pathological types.

Table 1. The characteristics of the subjects enrolled in the current study

\begin{tabular}{lllll}
\hline & CIN & Cervical Cancer & Control & $P$ value \\
\hline N & 358 & 547 & 567 & \\
Ages & $48.22 \pm 9.97$ & $48.01 \pm 9.53$ & $48.98 \pm 7.30$ & 0.125 \\
CIN1 & 34 & & & \\
CIN2-3 & 324 & & & \\
Histological types & & & & \\
SCC & & 447 & & \\
AC & & 87 & & \\
Others & 13 & & \\
Clinical stages & & & & \\
I & & 307 & & \\
II & & 213 & & \\
III & & 21 & & \\
IV & & 6 & & \\
Parity & & & & \\
Yes & 350 & 543 & & \\
No & 8 & 4 & & \\
HPV infection & & 535 & & \\
+ & 354 & 4 & 12 & \\
- & & & & \\
\hline
\end{tabular}

\section{Association of the seven SNPs with CIN and cervical cancer}

The association of these seven SNPs in miRNA genes with CIN and cervical cancer was analysed, and the results calculated using logistic regression are presented in Table 2 and Table 3 . The results showed that the $\mathrm{T}$ allele of $\mathrm{rs} 4636297$ in miR-126 was associated with higher risk of CIN $(P=0.019$; $O R=1.334,95 \% C I: 1.049-1.698)$ and cervical cancer $(P=0.019 ; O R=1.296 ; 95 \% C I: 1.044-1.349)$. The $\mathrm{T}$ allele of rs11614913 occurred more frequently in the control groups than in the cervical cancer groups $(P=0.025$ and 0.015), and it might be associated with a decreased risk for CIN (OR=0.807, 95\% CI: $0.669-0.974)$ and cervical cancer $(O R=0.814,95 \% C I$ : $0.689-0.961)$. Moreover, the genotypic frequencies for rs4636297 and rs11614913 were significantly different between the CIN and control groups $(P=0.003$ and 0.021 , respectively), and between the cervical cancer and control groups ( $P=0.028$ and 0.043 , respectively).

\section{Inheritance model analysis of these seven SNPs}

Three inheritance models (including codominant, dominant, and recessive) were analysed, and the results are shown in Table 4. The results showed that the TT genotype of rs4636297 was a risk factor for CIN (OR=3.611, 95\% CI: 1.624-8.030) and cervical cancer $(O R=2.343,95 \% \quad C I$ : 1.056-5.197) compared with C/C-C/T genotype. For rs11614913, the $\mathrm{T} / \mathrm{C}-\mathrm{C} / \mathrm{C}$ genotype was associated with a higher risk of CIN $(O R=1.556,95 \% \mathrm{CI}: 1.126-2.151)$ and cervical cancer $(O R=1.343,95 \% \quad C I:$ 1.018-1.771) compared with the $\mathrm{T} / \mathrm{T}$ genotype.

\section{Discussion}

Several studies have reported aberrant expression of miRNAs in various human cancers [25, 26]. Polymorphisms in miRNA genes could affect miRNA biological processes, resulting in miRNA deregulation that could be associated with cancer development[16, 27]. In the current study, we found that rs4636297 in pri-miR-126 and rs11614913 in miR-196a2 were associated with the progression of cervical cancer.

MiR-126 is located in intron 7 of egfl7 and plays important roles in angiogenesis and inflammation [28-30]. In most human cancers, miR-126 functions as a tumour suppressor, and studies have revealed the downregulation of miR-126 in cancerous tissues compared with noncancerous tissues[31-34]. In 2008, Wang et al. identified the downregulation of miR-126 in cervical cancer[35]. Rs4636297 is located $12 \mathrm{bp}$ downstream of the pre-miR-126 sequence, and this region might be associated with Drosha recognizing and cleaving the pri-miRNA[27]. Thus, this SNP might affect the expression of miR-126, and it could also be associated with human cancers. In the current study, we showed that rs4636297 in the miR-126 gene was associated with CIN and cervical cancer in a Chinese Han population. However, Yang et al. did not find an association between this SNP and breast cancer in German women[36]. The discrepancy might be because the two studies selected different populations with different genetic backgrounds. The frequency of the A allele of rs 4636297 is $36.4 \%$ in the European population, while it is only $18.7 \%$ in the East Asian population. The second reason for the discrepancy is that the two studies selected different diseases in which miR-126 might play different roles. However, it will be valuable to carry out functional and associational studies to explore the roles of rs4636297 in human cancers in the future, since the location of this SNP might affect biogenesis. 
Table 2. Allelic distribution of the SNPs in control, CIN and cervical cancer groups

\begin{tabular}{|c|c|c|c|c|c|c|c|c|}
\hline \multirow[t]{2}{*}{ SNPs } & \multirow[t]{2}{*}{ Alleles $(n, \%)$} & & \multicolumn{2}{|c|}{ Control VS CIN } & \multicolumn{2}{|c|}{ Control VS Cervical cancer } & \multicolumn{2}{|c|}{ CIN VS Cervical cancer } \\
\hline & & & $P$ value & OR $[95 \% C I]$ & $P$ value & OR $[95 \% C I]$ & $P$ value & OR[95\%CI] \\
\hline rs543412 & $\mathrm{C}$ & $\mathrm{T}$ & & & & & & \\
\hline Control & $677(59.7 \%)$ & $457(40.3 \%)$ & 0.261 & $0.895[0.738-1.086]$ & 0.765 & $0.974[0.822-1.155]$ & 0.422 & $1.083[0.892-1.314]$ \\
\hline $\mathrm{CIN}$ & $446(62.3 \%)$ & $270(37.7 \%)$ & & & & & & \\
\hline Cervical cancer & $661(60.4 \%)$ & $433(39.6 \%)$ & & & & & & \\
\hline rs999885 & A & G & & & & & & \\
\hline Control & $895(81.3 \%)$ & $239(18.7 \%)$ & 0.923 & $0.989[0.785-1.246]$ & 0.164 & $0.862[0.699-1.062]$ & 0.278 & $0.877[0.692-1.111]$ \\
\hline $\mathrm{CIN}$ & $568(79.3 \%)$ & $148(20.7 \%)$ & & & & & & \\
\hline Cervical cancer & $890(81.4 \%)$ & $204(18.6 \%)$ & & & & & & \\
\hline rs1143770 & $\mathrm{C}$ & $\mathrm{T}$ & & & & & & \\
\hline Control & $528(46.6 \%)$ & $606(53.4 \%)$ & 0.804 & $0.976[0.809-1.179]$ & 0.834 & $0.982[0.831-1.161]$ & 0.921 & $1.010[0.836-1.220]$ \\
\hline $\mathrm{CIN}$ & $329(46.0 \%)$ & $387(54.0 \%)$ & & & & & & \\
\hline Cervical cancer & $505(46.2 \%)$ & $589(53.8 \%)$ & & & & & & \\
\hline rs2296616 & $\mathrm{T}$ & $\mathrm{C}$ & & & & & & \\
\hline Control & $1052(92.8 \%)$ & $82(7.2 \%)$ & 0.567 & $1.109[0.779-1.578]$ & 0.849 & $0.969[0.704-1.334]$ & 0.668 & $1.080[0.759-1.537]$ \\
\hline $\mathrm{CIN}$ & $659(92.0 \%)$ & $57(8.0 \%)$ & & & & & & \\
\hline Cervical cancer & $1013(92.6 \%)$ & $81(7.4 \%)$ & & & & & & \\
\hline rs8111742 & A & G & & & & & & \\
\hline Control & $341(30.1 \%)$ & $793(69.9 \%)$ & 0.167 & $1.153[0.942-1.410]$ & 0.191 & $1.127[0.942-1.349]$ & 0.785 & $0.973[0.796-1.188]$ \\
\hline CIN & $238(32.4 \%)$ & $478(67.6 \%)$ & & & & & & \\
\hline Cervical cancer & $357(32.6 \%)$ & $737(67.4 \%)$ & & & & & & \\
\hline rs4636297 & $\mathrm{C}$ & $\mathrm{T}$ & & & & & & \\
\hline Control & $948(83.6 \%)$ & $186(16.4 \%)$ & 0.019 & $1.334[1.049-1.698]$ & 0.019 & $1.296[1.044-1.609]$ & 0.785 & $0.973[0.770-1.229]$ \\
\hline CIN & $569(79.5 \%$ & $147(20.5 \%)$ & & & & & & \\
\hline Cervical cancer & $874(79.9 \%)$ & $220(20.1 \%)$ & & & & & & \\
\hline rs11614913 & $\mathrm{C}$ & $\mathrm{T}$ & & & & & & \\
\hline Control & $546(48.1 \%)$ & $588(51.9 \%)$ & 0.025 & $0.807[0.669-0.974]$ & 0.015 & $0.814[0.689-0.961]$ & 0.938 & $1.008[0.834-1.217]$ \\
\hline CIN & $383(53.5 \%)$ & $333(46.5 \%)$ & & & & & & \\
\hline Cervical cancer & $583(53.3 \%)$ & $511(46.7 \%)$ & & & & & & \\
\hline
\end{tabular}

Table 3. Genotypic distribution of the seven SNPs in Control, CIN and Cervical cancer groups

\begin{tabular}{|c|c|c|c|c|c|c|}
\hline \multirow[t]{2}{*}{ SNPs } & \multirow{2}{*}{\multicolumn{2}{|c|}{ Genotypes $(n, \%)$}} & & \multicolumn{3}{|l|}{$P$ Value } \\
\hline & & & & Control VS CIN & Control VS Cervical cancer & CIN VS Cervical cancer \\
\hline rs543412 & $\mathrm{C} / \mathrm{C}$ & $\mathrm{C} / \mathrm{T}$ & $\mathrm{T} / \mathrm{T}$ & & & \\
\hline Control & $199(35.1 \%)$ & $279(49.2 \%)$ & $89(15.7 \%)$ & 0.253 & 0.739 & 0.577 \\
\hline CIN & $144(40.2 \%)$ & $158(44.1 \%)$ & $56(15.6 \%)$ & & & \\
\hline Cervical cancer & $203(37.1 \%)$ & $255(46.6 \%)$ & $89(16.3 \%)$ & & & \\
\hline rs999885 & $\mathrm{A} / \mathrm{A}$ & $\mathrm{A} / \mathrm{G}$ & $\mathrm{G} / \mathrm{G}$ & & & \\
\hline Control & $350(61.7 \%)$ & $195(34.4 \%)$ & $22(3.9 \%)$ & 0.159 & 0.112 & 0.542 \\
\hline CIN & $231(64.5 \%)$ & $106(29.6 \%)$ & $21(5.9 \%)$ & & & \\
\hline Cervical cancer & $367(67.1 \%)$ & $156(28.5 \%)$ & $24(4.4 \%)$ & & & \\
\hline rs1143770 & $\mathrm{C} / \mathrm{C}$ & $\mathrm{C} / \mathrm{T}$ & $\mathrm{T} / \mathrm{T}$ & & & \\
\hline Control & $118(20.8 \%)$ & $292(51.5 \%)$ & $157(27.7 \%)$ & 0.741 & 0.562 & 0.979 \\
\hline $\mathrm{CIN}$ & $77(21.5 \%)$ & $175(48.9 \%)$ & $106(29.6 \%)$ & & & \\
\hline Cervical cancer & $121(22.1 \%)$ & $263(48.1 \%)$ & $163(29.8 \%)$ & & & \\
\hline rs2296616 & $\mathrm{T} / \mathrm{T}$ & $\mathrm{T} / \mathrm{C}$ & $\mathrm{C} / \mathrm{C}$ & & & \\
\hline Control & $490(86.4 \%)$ & $72(12.7 \%)$ & $5(0.9 \%)$ & 0.291 & 0.447 & 0.852 \\
\hline CIN & $302(84.4 \%)$ & $55(15.4 \%)$ & $1(0.3 \%)$ & & & \\
\hline Cervical cancer & $468(85.5 \%)$ & $77(14.1 \%)$ & $2(0.4 \%)$ & & & \\
\hline rs8111742 & $\mathrm{A} / \mathrm{A}$ & $\mathrm{A} / \mathrm{G}$ & $\mathrm{G} / \mathrm{G}$ & & & \\
\hline Control & $48(8.5 \%)$ & $245(43.2 \%)$ & $274(48.3 \%)$ & 0.073 & 0.419 & 0.423 \\
\hline CIN & $47(13.1 \%)$ & $144(40.2 \%)$ & $167(46.6 \%)$ & & & \\
\hline Cervical cancer & $60(11.0 \%)$ & $237(43.3 \%)$ & $250(45.7 \%)$ & & & \\
\hline rs4636297 & $\mathrm{C} / \mathrm{C}$ & $\mathrm{C} / \mathrm{T}$ & $\mathrm{T} / \mathrm{T}$ & & & \\
\hline Control & $390(68.8 \%)$ & $168(29.6 \%)$ & $9(5.6 \%)$ & 0.003 & 0.028 & 0.289 \\
\hline $\mathrm{CIN}$ & $231(64.5 \%)$ & $107(29.9 \%)$ & $20(5.6 \%)$ & & & \\
\hline Cervical cancer & $347(63.4 \%)$ & $180(32.9 \%)$ & $20(3.7 \%)$ & & & \\
\hline rs11614913 & $\mathrm{T} / \mathrm{T}$ & $\mathrm{T} / \mathrm{C}$ & $\mathrm{C} / \mathrm{C}$ & & & \\
\hline Control & $153(27.0 \%)$ & $282(49.7 \%)$ & $132(23.3 \%)$ & 0.021 & 0.043 & 0.442 \\
\hline $\mathrm{CIN}$ & $68(19.0 \%)$ & $197(55.0 \%)$ & $93(26.0 \%)$ & & & \\
\hline Cervical cancer & $117(21.4 \%)$ & $277(50.6 \%)$ & $153(28.0 \%)$ & & & \\
\hline
\end{tabular}

Table 4. The inheritance model analysis of the seven SNPs in miRNA genes among Control, CIN and Cervical cancer groups 


\begin{tabular}{|c|c|c|c|c|c|c|c|c|c|c|c|}
\hline \multirow[t]{2}{*}{ SNPs } & \multirow[t]{2}{*}{ Models } & \multirow[t]{2}{*}{ Genotypes } & \multirow[t]{2}{*}{$\begin{array}{l}\text { Control } \\
(n, \%)\end{array}$} & \multirow[t]{2}{*}{$\begin{array}{l}\text { CIN } \\
(n, \%)\end{array}$} & \multirow{2}{*}{$\begin{array}{l}\text { Cervical } \\
\text { cancer } \\
(n, \%)\end{array}$} & \multicolumn{2}{|l|}{ CIN VS Control } & \multicolumn{2}{|l|}{$\begin{array}{l}\text { Cervical cancer VS } \\
\text { Control }\end{array}$} & \multicolumn{2}{|c|}{ Cervical cancer VS CIN } \\
\hline & & & & & & OR $[95 \% C I]$ & $P$ value & OR $[95 \% C I]$ & $P$ value & OR $[95 \% C I]$ & $P$ value \\
\hline \multirow[t]{7}{*}{ rs543412 } & Codominant & $\mathrm{C} / \mathrm{C}$ & $199(35.1 \%)$ & $144(40.2 \%)$ & $203(37.1 \%)$ & 1 & 0.259 & 1 & 0.724 & 1 & 0.641 \\
\hline & & $\mathrm{C} / \mathrm{T}$ & $279(49.2 \%)$ & $158(44.1 \%)$ & $255(46.6 \%)$ & $0.784[0.587-1.048]$ & & $0.904[0.697-1.172]$ & & $1.145[0.855-1.532]$ & \\
\hline & & $\mathrm{T} / \mathrm{T}$ & $89(15.7 \%)$ & $56(15.6 \%)$ & $89(16.3 \%)$ & $0.863[0.580-1.285]$ & & $0.985[0.692-1.404]$ & & $1.127[0.758-1.676]$ & \\
\hline & Dominant & $\mathrm{C} / \mathrm{C}$ & $199(35.1 \%)$ & $144(40.2 \%)$ & 203(37.1\%) & 1 & 0.116 & 1 & 0.527 & 1 & 0.347 \\
\hline & & C/T-T-T & $368(64.9 \%)$ & $214(59.8 \%)$ & $344(62.9 \%)$ & $0.804[0612-1.056]$ & & $0.924[0.723-1.181]$ & & $1.140[0.867-1.499]$ & \\
\hline & Recessive & C/C-C-T & $478(84.3 \%)$ & $302(84.4 \%)$ & $458(83.7 \%)$ & 1 & 0.947 & 1 & 0.794 & 1 & 0.800 \\
\hline & & $\mathrm{T} / \mathrm{T}$ & $89(15.7 \%)$ & $56(15.6 \%)$ & $89(16.3 \%)$ & 0988[0.686-1.422] & & $1.044[0.757-1.439]$ & & $1.048[0.728-1.509]$ & \\
\hline \multirow[t]{7}{*}{ rs999885 } & Codominant & $\mathrm{A} / \mathrm{A}$ & $350(61.7 \%)$ & $231(64.5 \%)$ & $367(67.1 \%)$ & 1 & 0.170 & 1 & 0.101 & 1 & 0.552 \\
\hline & & A/G & $195(34.4 \%)$ & $106(29.6 \%)$ & $156(28.5 \%)$ & $0.826[0.619-1.104]$ & & $0.760[0.588-0.983]$ & & $0.927[0.689-1.248]$ & \\
\hline & & G/G & $22(3.9 \%)$ & $21(5.9 \%)$ & $24(4.4 \%)$ & $1.442[0.775-2.683]$ & & $1.056[0.581-1.921]$ & & $0.725[0.394-1.334]$ & \\
\hline & Dominant & $\mathrm{A} / \mathrm{A}$ & $350(61.7 \%)$ & $231(64.5 \%)$ & $367(67.1 \%)$ & 1 & 0.402 & 1 & 0.061 & 1 & 0.435 \\
\hline & & A/G-G/G & $217(38.3 \%)$ & $127(35.5 \%)$ & $180(32.9 \%)$ & $0.889[0.675-1.170]$ & & $0.790[0.618-1.011]$ & & $0.894[0.675-1.184]$ & \\
\hline & Recessive & A/A-A/G & $545(96.1 \%)$ & $337(94.1 \%)$ & $523(95.6 \%)$ & 1 & 0.170 & 1 & 0.855 & 1 & 0.332 \\
\hline & & $\mathrm{G} / \mathrm{G}$ & $22(3.9 \%)$ & $21(5.9 \%)$ & $24(4.4 \%)$ & $1.537[0.832-2.839]$ & & $1.155[0.639-2.088]$ & & $0.742[0.406-1.358]$ & \\
\hline \multirow[t]{7}{*}{ rs1143770 } & Codominant & $\mathrm{C} / \mathrm{C}$ & $118(20.8 \%)$ & $77(21.5 \%)$ & $121(22.1 \%)$ & 1 & 0.741 & 1 & 0.504 & 1 & 0.964 \\
\hline & & $\mathrm{C} / \mathrm{T}$ & $292(51.5 \%)$ & $175(48.9 \%)$ & $263(48.1 \%)$ & $0.925[0.656-1.304]$ & & $0.877[0.647-1.189]$ & & $0.956[0.678-1.348]$ & \\
\hline & & $\mathrm{T} / \mathrm{T}$ & $157(27.7 \%)$ & $106(29.6 \%)$ & $163(29.8 \%)$ & $1.041[0.713-1.520]$ & & $1.016[0.726-1.421]$ & & $0.981[0.673-1.429]$ & \\
\hline & Dominant & $\mathrm{C} / \mathrm{C}$ & $118(20.8 \%)$ & $77(21.5 \%)$ & $121(22.1 \%)$ & 1 & 0.832 & 1 & 0.596 & 1 & 0.832 \\
\hline & & $\mathrm{C} / \mathrm{T}-\mathrm{T} / \mathrm{T}$ & $449(79.2 \%)$ & $281(78.5 \%)$ & $426(77.9 \%)$ & $0.966[0.0 .698-1.335]$ & & $0.925[0.695-1.233]$ & & $0.966[0.698-1.335]$ & \\
\hline & Recessive & $\mathrm{C} / \mathrm{C}-\mathrm{C} / \mathrm{T}$ & $410(72.3 \%)$ & $252(70.4 \%)$ & $384(71.2 \%)$ & 1 & 0.525 & 1 & 0.419 & 1 & 0.419 \\
\hline & & $\mathrm{T} / \mathrm{T}$ & $157(27.7 \%)$ & $106(29.6 \%)$ & $163(29.8 \%)$ & 21-1.473] & & [0.858-1.444] & & $0.858-1.444]$ & \\
\hline \multirow[t]{7}{*}{ rs2296616 } & Codominant & $\mathrm{T} / \mathrm{T}$ & $490(86.4 \%)$ & $302(84.4 \%)$ & $468(85.5 \%)$ & 1 & 0.305 & 1 & 0.467 & 1 & 0.848 \\
\hline & & $\mathrm{T} / \mathrm{C}$ & $72(12.7 \%)$ & $55(15.4 \%)$ & $77(14.1 \%)$ & 20] & & $-1.596]$ & & [-1.315] & \\
\hline & & $\mathrm{C} / \mathrm{C}$ & $5(0.9$ & $1(0.3$ & $2(0$. & $.038-2.818]$ & & $1.016[0.726-1.421]$ & & $1.290[0.116-14.292]$ & \\
\hline & Dominant & $\mathrm{T} / \mathrm{T}$ & $490(86.4 \%)$ & $302(84.4 \%)$ & $468(85.5 \%)$ & 1 & 0.371 & 1 & 0.640 & 1 & 0.620 \\
\hline & & $\mathrm{T} / \mathrm{C}-\mathrm{C} / \mathrm{C}$ & $77(13.6 \%)$ & $56(15.6 \%)$ & $79(14.5 \%)$ & $1.186[0.816-1.723]$ & & $\begin{array}{l}1.084[0.772 \\
-1.522]\end{array}$ & & 20] & \\
\hline & Recessive & $\mathrm{T} / \mathrm{T}-\mathrm{T} / \mathrm{C}$ & $562(9$ & $357(99.7 \%)$ & $545(99.6 \%)$ & 1 & 0.296 & 1 & 0.306 & 1 & 0.826 \\
\hline & & $\mathrm{C} / \mathrm{C}$ & $5\left(0.9^{9}\right.$ & $1(0.3 \%)$ & $4(0.4 \%)$ & {$[0.037-2.730]$} & & $0.424[0.082-2.195]$ & & $1.310[0.118-14.498]$ & \\
\hline \multirow[t]{7}{*}{ rs8111742 } & Codominant & $\mathrm{A} / \mathrm{A}$ & $48(8.5$ & $47(13.1 \%)$ & $60(11$. & 1 & 0.089 & 1 & 0.309 & 1 & 0.501 \\
\hline & & A/G & $245(4$ & $144(40$. & $237(4$ & 0.6 & & 61] & & 90] & \\
\hline & & $\mathrm{G} / \mathrm{G}$ & 274( & $167(4$ & 250( & [0.404-0.988] & & $0.721[0.475-1.095]$ & & $1.173[0.763-1.801]$ & \\
\hline & Dominant & $\mathrm{A} / \mathrm{A}$ & $48(8$ & $44(1$ & & 1 & 0.058 & 1 & 0.142 & 1 & 0.326 \\
\hline & & A/G-C & 519 & & & $0.661[0.435-1.023]$ & & $0.741[0.496-1.105]$ & & $1.226[0.8$ & \\
\hline & Recessive & A/A-A/G & $293(51.6 \%)$ & $188(53.4 \%)$ & $297(54.3 \%)$ & 1 & 0.794 & 1 & 0.385 & 1 & 0.781 \\
\hline & & $\mathrm{G} / \mathrm{G}$ & $274(48$ & $170(46.6 \%)$ & $250(45.7 \%)$ & $0.937[0.719-1.222]$ & & $0.901[0.711-1.140]$ & & $0.963[0.737-1.258]$ & \\
\hline \multirow[t]{7}{*}{ rs4636297 } & Codominant & $\mathrm{C} / \mathrm{C}$ & $390(68.8 \%)$ & $231(64.5 \%)$ & $347(63.4 \%)$ & 1 & 0.006 & 1 & 0.036 & 1 & 0.288 \\
\hline & & $\mathrm{C} / \mathrm{T}$ & $168(29.6 \%)$ & $107(29.9 \%)$ & $180(32.9 \%)$ & 1.08 & & 771] & & 1.12 & \\
\hline & & $\mathrm{T} / \mathrm{T}$ & $9(5.6 \%)$ & $20(5.6 \%)$ & $20(3.7 \%)$ & $3.703[1.657-8.275]$ & & 2.494[1.120-5.557] & & $0.665[0.350-1.263]$ & \\
\hline & Dominant & $\mathrm{C} / \mathrm{C}$ & $390(68.8 \%)$ & $231(64.5 \%)$ & $347(63.4 \%)$ & 1 & 0.163 & 1 & & 1 & 0.732 \\
\hline & & $\mathrm{C} / \mathrm{T}-\mathrm{T} / \mathrm{T}$ & $177(31.2 \%)$ & $127(35.5 \%)$ & $200(36.6 \%)$ & $1.221[0.922-1.617]$ & & $1.282[0.999-1.644]$ & & $1.050[0.795-1.386]$ & \\
\hline & Recessive & $\mathrm{C} / \mathrm{C}-\mathrm{C} / \mathrm{T}$ & $558(98.4 \%)$ & $338(94.4 \%)$ & $527(96.3 \%)$ & 1 & 0.002 & 1 & 0.036 & 1 & 0.168 \\
\hline & & $\mathrm{T} / \mathrm{T}$ & $39(1.6 \%)$ & $20(5.6 \%)$ & $20(3.7 \%)$ & $3.611[1.624-8.030]$ & & $2.343[1.056-5.197]$ & & $0.640[0.339-1.208]$ & \\
\hline \multirow[t]{7}{*}{ rs11614913 } & Codominant & $\mathrm{T} / \mathrm{T}$ & $153(27.0 \%)$ & $68(19.0 \%)$ & $117(21.4 \%)$ & 1 & 0.028 & 1 & 0.043 & 1 & 0.417 \\
\hline & & $\mathrm{T} / \mathrm{C}$ & $282(49.7 \%)$ & $197(55.0 \%)$ & $277(50.6 \%)$ & $1.547[1.101-2.174]$ & & $1.268[0.946-1.700]$ & & $0.816[0.574-1.158]$ & \\
\hline & & $\mathrm{C} / \mathrm{C}$ & $132(23.3 \%)$ & $93(26.0 \%)$ & $153(28.0 \%)$ & $1.575[1.066-2.327]$ & & $1.503[1.074-2.102]$ & & $0.955[0.644-1.418]$ & \\
\hline & Dominant & $\mathrm{T} / \mathrm{T}$ & $153(27.0 \%)$ & $68(19.0 \%)$ & $117(21.4 \%)$ & 1 & 0.007 & 1 & 0.037 & 1 & 0.377 \\
\hline & & $\mathrm{T} / \mathrm{C}-\mathrm{C} / \mathrm{C}$ & $414(73.0 \%)$ & $290(81.0 \%)$ & $430(78.6 \%)$ & $1.556[1.126-2.151]$ & & $1.343[1.018-1.771]$ & & $0.860[0.616-1.202]$ & \\
\hline & Recessive & $\mathrm{T} / \mathrm{T}-\mathrm{T} / \mathrm{C}$ & $435(76.7 \%)$ & $265(74.0 \%)$ & $394(72.0 \%)$ & 1 & 0.337 & 1 & 0.074 & 1 & 0.508 \\
\hline & & $\mathrm{C} / \mathrm{C}$ & $132(23.3 \%)$ & $93(26.0 \%)$ & $153(28.0 \%)$ & $1.162[0.855-1.579]$ & & $1.280[0.977-1.677]$ & & $1.107[0.819-1.498]$ & \\
\hline
\end{tabular}

SNP rs11614913, a polymorphism site in mature miR-196a2, has been widely studied in various human cancers, and the results of such studies indicated that rs11614913 was associated with various human cancers [37-40]; however, Zhang et al. found a lack of association between this SNP and gastric cancer[41]. In the current study, our results showed that this SNP was associated with CIN and cervical cancer in the Chinese Han population. Furthermore, the $\mathrm{C}$ allele of rs11614913 might be a risk factor for CIN and cervical cancer. Our result was consistent with the Thakur et al results[42]. In 2016, Torruella-Loran et al. found that rs11614913 in miR-196a2 has a function in regulating the expression of several genes involved in cancer[43]. SNPs located in the mature sequences of miRNA genes might affect miRNA biogenesis and recognition of target mRNAs[16]. As rs11614913 is located in the mature sequence of miR-196a2, our results indicated that rs11614913 might be associated with cervical cancer in this way.

The roles of miR-107 are different for different cancers. For example miR-107 is a suppressor of breast 
cancer[44, 45], renal cancer[46] and glioma[47]; in contrast, this miRNA can promote human gastric cancer[48, 49] and hepatocellular carcinoma[50]. In 2014, Wang et al. found that the TT genotype of rs2296616 was a risk factor for gastric cancer[51]. In addition, they also found that the TT genotype was associated with higher miR-107 expression than the CC genotype[51]. MiR-125a is a suppressor of colon cancer[52], prostate cancer[53], ovarian cancer[54], breast cancer[55] and prostate cancer[56]. In cervical cancer, miR-125a suppresses tumour growth, invasion and metastasis by targeting STAT3. In 2016, Xu et al. [57] reported that the AA genotype of rs 8111742 in miR-125a increased the risk for gastric cancer associated with H. pylori, and this same effect was found by Wu et al. [58] in the H. pylori-positive group. SNP rs999885, located at the promoter region of the miR-106b-25 cluster, has been reported to be associated with the risk for hepatocellular carcinoma[59]. It was reported that rs1143770 in the let7-a-2 gene is associated with non-small-cell lung cancer[60] but not gastric cancer[61]. In the current study, we did not find that rs2296616, rs8111742, rs999885 and rs1143770 were associated with cervical cancer. The reasons for these differences between the other studies and the current study could be the various roles of the same miRNAs in different human cancers, and this possibility is supported by the tissue-specific expression of miRNAs[62]. Thus, it is necessary to investigate the function of the SNPs in miRNA genes in specific tissues.

\section{Conclusion}

The current study investigated the association of seven SNPs in miRNA genes (rs543412 in miR-100, rs999885 in miR-106b, rs1143770 in let7-a-2, rs2296616 in miR-107, rs8111742 in miR-125a, rs4636297 in miR-126 and rs11614913 in miR-196a2) with the initiation (control VS CIN) and development of cervical cancer (CIN VS cervical cancer). The results showed that rs4636297 and rs11614913 were associated with the risk of CIN and cervical cancer. However, these two SNPs did not play roles in the progression from CIN to cervical cancer. Therefore, rs4636297 in miR-126, and rs11614913 in miR-196a2, might only be associated with the initiation of cervical cancer, not the development of CIN to cervical cancer.

\section{Acknowledgements}

Our great gratitude was expressed to the participation of the patients and control subjects in current study. This work was supported by grants from the National Science Foundation of China (81573206 and 31270030), Yunnan Applied Basic Research Projects (2016FA034), Fundamental
Research Funds for the Central Universities and the PUMC Youth Fund (3332015149), The Association Foundation Program of Yunnan Provincial Science and Technology Department and Kunming Medical University (2017FE467-077, 2017NS189, 2017FE467012 and 2018FE001-254), Special Funds for high-level health talents of Yunnan Province (D-201669 and L-201615) and CAMS Innovation Fund for Medical Sciences (2016-I2M-2-001). The funders had no role in study design, data collection and analysis, decision to publish or preparation of the manuscript.

\section{Competing Interests}

The authors have declared that no competing interest exists.

\section{References}

1. Torre LA, Bray F, Siegel RL, Ferlay J, Lortet-Tieulent J, Jemal A. Global cancer statistics, 2012. CA: a cancer journal for clinicians. 2015; 65: 87-108.

2. Walboomers JM, Jacobs MV, Manos MM, Bosch FX, Kummer JA, Shah KV, et al. Human papillomavirus is a necessary cause of invasive cervical cancer worldwide. The Journal of pathology. 1999; 189: 12-9.

3. Moscicki AB, Shiboski S, Broering J, Powell K, Clayton L, Jay N, et al. The natural history of human papillomavirus infection as measured by repeated DNA testing in adolescent and young women. The Journal of pediatrics. 1998; 132: 277-84.

4. Moscicki AB, Widdice L, Ma Y, Farhat S, Miller-Benningfield S, Jonte J, et al. Comparison of natural histories of human papillomavirus detected by clinician- and self-sampling. International journal of cancer. 2010; 127: 1882-92.

5. Ho GY, Burk RD, Klein S, Kadish AS, Chang CJ, Palan P, et al. Persistent genital human papillomavirus infection as a risk factor for persistent cervical dysplasia. Journal of the National Cancer Institute. 1995; 87: 1365-71.

6. Munoz N, Franceschi S, Bosetti C, Moreno V, Herrero R, Smith JS, et al. Role of parity and human papillomavirus in cervical cancer: the IARC multicentric case-control study. Lancet (London, England). 2002; 359: 1093-101.

7. Comparison of risk factors for invasive squamous cell carcinoma and adenocarcinoma of the cervix: collaborative reanalysis of individual data on 8,097 women with squamous cell carcinoma and 1,374 women with adenocarcinoma from 12 epidemiological studies. International journal of cancer. 2007; 120: 885-91.

8. Zhang X, Dai B, Zhang B, Wang Z. Vitamin A and risk of cervical cancer: a meta-analysis. Gynecologic oncology. 2012; 124: 366-73.

9. Valencia-Sanchez MA, Liu J, Hannon GJ, Parker R. Control of translation and mRNA degradation by miRNAs and siRNAs. Genes \& development. 2006; 20 : 515-24.

10. Piccoli MT, Gupta SK, Thum T. Noncoding RNAs as regulators of cardiomyocyte proliferation and death. Journal of molecular and cellular cardiology. 2015; 89: 59-67.

11. Chen Y, Fu LL, Wen X, Liu B, Huang J, Wang JH, et al. Oncogenic and tumor suppressive roles of microRNAs in apoptosis and autophagy. Apoptosis. 2014; 19: 1177-89.

12. Luo D, Wilson JM, Harvel N, Liu J, Pei L, Huang S, et al. A systematic evaluation of miRNA:mRNA interactions involved in the migration and invasion of breast cancer cells. Journal of translational medicine. 2013; 11: 57.

13. Srivastava SK, Ahmad A, Zubair H, Miree O, Singh S, Rocconi RP, et al. MicroRNAs in gynecological cancers: Small molecules with big implications. Cancer letters. 2017; 407: 123-38.

14. Dai S, Lu Y, Long Y, Lai Y, Du P, Ding N, et al. Prognostic value of microRNAs in cervical carcinoma: a systematic review and meta-analysis. Oncotarget. 2016; 7: 35369-78.

15. Oi P, Wang L, Zhou B, Yao WJ, Xu S, Zhou $Y$, et al. Associations of miRNA polymorphisms and expression levels with breast cancer risk in the Chinese population. Genetics and molecular research : GMR. 2015; 14: 6289-96.

16. Kroliczewski J, Sobolewska A, Lejnowski D, Collawn JF, Bartoszewski R. microRNA single polynucleotide polymorphism influences on microRNA biogenesis and mRNA target specificity. Gene. 2018; 640: 66-72.

17. $\mathrm{Hu} \mathrm{Y,} \mathrm{Yu} \mathrm{CY,} \mathrm{Wang} \mathrm{JL,} \mathrm{Guan} \mathrm{J,} \mathrm{Chen} \mathrm{HY,} \mathrm{Fang} \mathrm{JY.} \mathrm{MicroRNA} \mathrm{sequence}$ polymorphisms and the risk of different types of cancer. Scientific reports. 2014; 4: 3648.

18. Ma XP, Zhang T, Peng B, Yu L, Jiang de K. Association between microRNA polymorphisms and cancer risk based on the findings of 66 case-control studies. PloS one. 2013; 8: e79584.

19. Xu Q, Liu JW, Yuan Y. Comprehensive assessment of the association between miRNA polymorphisms and gastric cancer risk. Mutation research Reviews in mutation research. 2015; 763: 148-60. 
20. Salzman DW, Weidhaas JB. SNPing cancer in the bud: microRNA and microRNA-target site polymorphisms as diagnostic and prognostic biomarkers in cancer. Pharmacology \& therapeutics. 2013; 137: 55-63.

21. Li C, Zhang Y, Li Y, Ma Q, Liu S, Yao Y, et al. The association of polymorphisms in miRNAs with nonsmall cell lung cancer in a Han Chinese population. Cancer management and research. 2018; 10: 697-704.

22. Jia ZF, Cao DH, Wu YH, Jin MS, Pan YC, Cao XY, et al. Lethal-7-related polymorphisms are associated with susceptibility to and prognosis of gastric cancer. World journal of gastroenterology. 2019; 25: 1012-23.

23. Wang S, Cao X, Ding B, Chen J, Cui M, Xu Y, et al. The rs767649 polymorphism in the promoter of miR-155 contributes to the decreased risk for cervical cancer in a Chinese population. Gene. 2016; 595: 109-14.

24. Chuanyin L, Xiaona W, Zhiling Y, Yu Z, Shuyuan L, Jie Y, et al. The association between polymorphisms in microRNA genes and cervical cancer in a Chinese Han population. Oncotarget. 2017; 8: 87914-27.

25. Li J, Liu Q, Clark LH, Qiu H, Bae-Jump VL, Zhou C. Deregulated miRNAs in human cervical cancer: functional importance and potential clinical use. Future oncology (London, England). 2017; 13: 743-53.

26. Wang QX, Zhu YQ, Zhang H, Xiao J. Altered MiRNA expression in gastric cancer: a systematic review and meta-analysis. Cellular physiology and biochemistry : international journal of experimental cellular physiology, biochemistry, and pharmacology. 2015; 35: 933-44.

27. Ha M, Kim VN. Regulation of microRNA biogenesis. Nature reviews Molecular cell biology. 2014; 15: 509-24.

28. Fish JE, Santoro MM, Morton SU, Yu S, Yeh RF, Wythe JD, et al. miR-126 regulates angiogenic signaling and vascular integrity. Developmental cell. 2008; $15: 272-84$

29. Wang S, Aurora AB, Johnson BA, Qi X, McAnally J, Hill JA, et al. The endothelial-specific microRNA miR-126 governs vascular integrity and angiogenesis. Developmental cell. 2008; 15: 261-71.

30. Feng S, Wang L, Liu W, Zhong Y, Xu S. MiR-126 correlates with increased disease severity and promotes keratinocytes proliferation and inflammation while suppresses cells' apoptosis in psoriasis. 2018: e22588.

31. Yanaihara N, Caplen N, Bowman E, Seike M, Kumamoto K, Yi M, et al. Unique microRNA molecular profiles in lung cancer diagnosis and prognosis. Cancer cell. 2006; 9: 189-98.

32. Cho WC, Chow AS, Au JS. Restoration of tumour suppressor hsa-miR-145 inhibits cancer cell growth in lung adenocarcinoma patients with epidermal growth factor receptor mutation. European journal of cancer (Oxford, England : 1990). 2009; 45: 2197-206.

33. Feng R, Chen $X, Y u$ Y, Su L, Yu B, Li J, et al. miR-126 functions as a tumour suppressor in human gastric cancer. Cancer letters. 2010; 298: 50-63.

34. Saito Y, Friedman JM, Chihara Y, Egger G, Chuang JC, Liang G. Epigenetic therapy upregulates the tumor suppressor microRNA-126 and its host gene EGFL7 in human cancer cells. Biochemical and biophysical research communications. 2009; 379: 726-31.

35. Wang X, Tang S, Le SY, Lu R, Rader JS, Meyers C, et al. Aberrant expression of oncogenic and tumor-suppressive microRNAs in cervical cancer is required for cancer cell growth. PloS one. 2008; 3: e2557.

36. Yang R, Dick M, Marme F, Schneeweiss A, Langheinz A, Hemminki K, et al. Genetic variants within miR-126 and miR-335 are not associated with breast cancer risk. Breast cancer research and treatment. 2011; 127: 549-54.

37. Kang Z, Li Y, He X, Jiu T, Wei J, Tian F, et al. Quantitative assessment of the association between miR-196a2 rs11614913 polymorphism and cancer risk: evidence based on 45,816 subjects. Tumour biology : the journal of the International Society for Oncodevelopmental Biology and Medicine. 2014; 35: 6271-82

38. Wang $\mathrm{YH}, \mathrm{Hu} \mathrm{HN}$, Weng $\mathrm{H}$, Chen $\mathrm{H}$, Luo CL, Ji J, et al. Association between Polymorphisms in MicroRNAs and Risk of Urological Cancer: A Meta-Analysis Based on 17,019 Subjects. Frontiers in physiology. 2017; 8: 325.

39. Rakmanee S, Pakakasama S, Hongeng S, Sanguansin S, Thongmee A, Pongstaporn W. Increased Risk of Thai Childhood Acute Lymphoblastic Leukemia with the MiR196a2 T $>$ C Polymorphism. Asian Pacific journal of cancer prevention : APJCP. 2017; 18: 1117-20.

40. Zheng L, Zhuang C, Zhao J, Ming L. Functional miR-146a, miR-149, miR-196a2 and miR-499 polymorphisms and the susceptibility to hepatocellular carcinoma: An updated meta-analysis. Clinics and research in hepatology and gastroenterology. 2017; 41: 664-76.

41. Zhang L, Gao J, Zhou D, Bao F. Lack of association of two common polymorphisms rs2910164 and rs11614913 with susceptibility to gastric cancer: A meta-analysis. The Turkish journal of gastroenterology : the official journal of Turkish Society of Gastroenterology. 2015; 26: 378-85.

42. Thakur N, Singhal P, Mehrotra R, Bharadwaj M. Impacts of single nucleotide polymorphisms in three microRNAs (miR-146a, miR-196a2 and miR-499) on the susceptibility to cervical cancer among Indian women. 2019; 39.

43. Torruella-Loran I, Laayouni H, Dobon B, Gallego A, Balcells I, Garcia-Ramallo E, et al. MicroRNA Genetic Variation: From Population Analysis to Functional Implications of Three Allele Variants Associated with Cancer. Human mutation. 2016; 37: 1060-73

44. Li XY, Luo QF, Wei CK, Li DF, Li J, Fang L. MiRNA-107 inhibits proliferation and migration by targeting CDK8 in breast cancer. International journal of clinical and experimental medicine. 2014; 7: 32-40.

45. Zhang L, Ma P, Sun LM, Han YC, Li BL, Mi XY, et al. MiR-107 down-regulates SIAH1 expression in human breast cancer cells and silencing of miR-107 inhibits tumor growth in a nude mouse model of triple-negative breast cancer. Molecular carcinogenesis. 2016; 55: 768-77

46. Song N, Ma X, Li H, Zhang Y, Wang X, Zhou P, et al. microRNA-107 functions as a candidate tumor suppressor gene in renal clear cell carcinoma involving multiple genes. Urologic oncology. 2015; 33: 205.e1-11.

47. Chen L, Li ZY, Xu SY, Zhang XJ, Zhang Y, Luo K, et al. Upregulation of miR-107 Inhibits Glioma Angiogenesis and VEGF Expression. Cellular and molecular neurobiology. 2016; 36: 113-20.

48. Ayremlou N, Mozdarani H, Mowla SJ, Delavari A. Increased levels of serum and tissue miR-107 in human gastric cancer: Correlation with tumor hypoxia. Cancer biomarkers : section A of Disease markers. 2015; 15: 851-60.

49. Zhang M, Wang X, Li W, Cui Y. miR-107 and miR-25 simultaneously target LATS2 and regulate proliferation and invasion of gastric adenocarcinoma (GAC) cells. Biochemical and biophysical research communications. 2015; 460: 806-12.

50. Zhang JJ, Wang CY, Hua L, Yao KH, Chen JT, Hu JH. miR-107 promotes hepatocellular carcinoma cell proliferation by targeting Axin2. International journal of clinical and experimental pathology. 2015; 8: 5168-74.

51. Wang S, Lv C, Jin $\mathrm{H}, \mathrm{Xu} \mathrm{M}$, Kang $\mathrm{M}, \mathrm{Chu} \mathrm{H}$, et al. A common genetic variation in the promoter of miR-107 is associated with gastric adenocarcinoma susceptibility and survival. Mutation research. 2014; 769: 35-41.

52. Tong Z, Liu N, Lin L, Guo X, Yang D, Zhang Q. miR-125a-5p inhibits cell proliferation and induces apoptosis in colon cancer via targeting BCL2, BCL2L12 and MCL1. Biomedicine \& pharmacotherapy = Biomedecine \& pharmacotherapie. 2015; 75: 129-36.

53. Fu Y, Cao F. MicroRNA-125a-5p regulates cancer cell proliferation and migration through NAIF1 in prostate carcinoma. OncoTargets and therapy. 2015; 8: 3827-35.

54. Yang J, Li G, Zhang K. MiR-125a regulates ovarian cancer proliferation and invasion by repressing GALNT14 expression. Biomedicine \& pharmacotherapy = Biomedecine \& pharmacotherapie. 2016; 80: 381-7.

55. Sun Y, Liu X, Zhang Q, Mao X, Feng L, Su P, et al. Oncogenic potential of TSTA3 in breast cancer and its regulation by the tumor suppressors miR-125a-5p and miR-125b. Tumour biology : the journal of the International Society for Oncodevelopmental Biology and Medicine. 2016; 37: 4963-72.

56. Ninio-Many L, Grossman H, Levi M, Zilber S, Tsarfaty I, Shomron N, et al. MicroRNA miR-125a-3p modulates molecular pathway of motility and migration in prostate cancer cells. Oncoscience. 2014; 1: 250-61.

57. Xu Q, Wu YF, Li Y, He CY, Sun LP, Liu JW, et al. SNP-SNP interactions of three new pri-miRNAs with the target gene PGC and multidimensional analysis of $\mathrm{H}$. pylori in the gastric cancer/atrophic gastritis risk in a Chinese population. Oncotarget. 2016; 7: 23700-14.

58. Wu YF, Xu Q, He CY, Li Y, Liu JW, Deng N, et al. Association of Polymorphisms in three pri-miRNAs that Target Pepsinogen $C$ with the Risk and Prognosis of Gastric Cancer. Scientific reports. 2017; 7: 39528.

59. Liu Y, Zhang Y, Wen J, Liu L, Zhai X, Liu J, et al. A genetic variant in the promoter region of miR-106b-25 cluster and risk of HBV infection and hepatocellular carcinoma. PloS one. 2012; 7: e32230.

60. Shin KM, Jung DK, Hong MJ, Kang HJ, Lee WK, Yoo SS, et al. The pri-let-7a-2 rs1143770C $>\mathrm{T}$ is associated with prognosis of surgically resected non-small cell lung cancer. Gene. 2016; 577: 148-52.

61. Xu Q, Dong $\mathrm{Q}, \mathrm{He} \mathrm{C}$, Liu W, Sun L, Liu J, et al. A new polymorphism biomarker rs629367 associated with increased risk and poor survival of gastric cancer in chinese by up-regulated miRNA-let-7a expression. PloS one. 2014; 9: e95249.

62. Guo Z, Maki M, Ding R, Yang Y, Zhang B, Xiong L. Genome-wide survey of tissue-specific microRNA and transcription factor regulatory networks in 12 tissues. Scientific reports. $2014 ; 4 \cdot 5150$. 